Document downloaded from:

http://hdl.handle.net/10251/70779

This paper must be cited as:

García García, P.; Zagdoun, A.; Coperet, C.; Lesage, A.; Díaz Morales, UM.; Corma Canós, A. (2013). In situ preparation of a multifunctional chiral hybrid organic-inorganic catalyst for asymmetric multicomponent reactions. Chemical Science. 4(5):2006-2012. doi:10.1039/C3SC22310H.

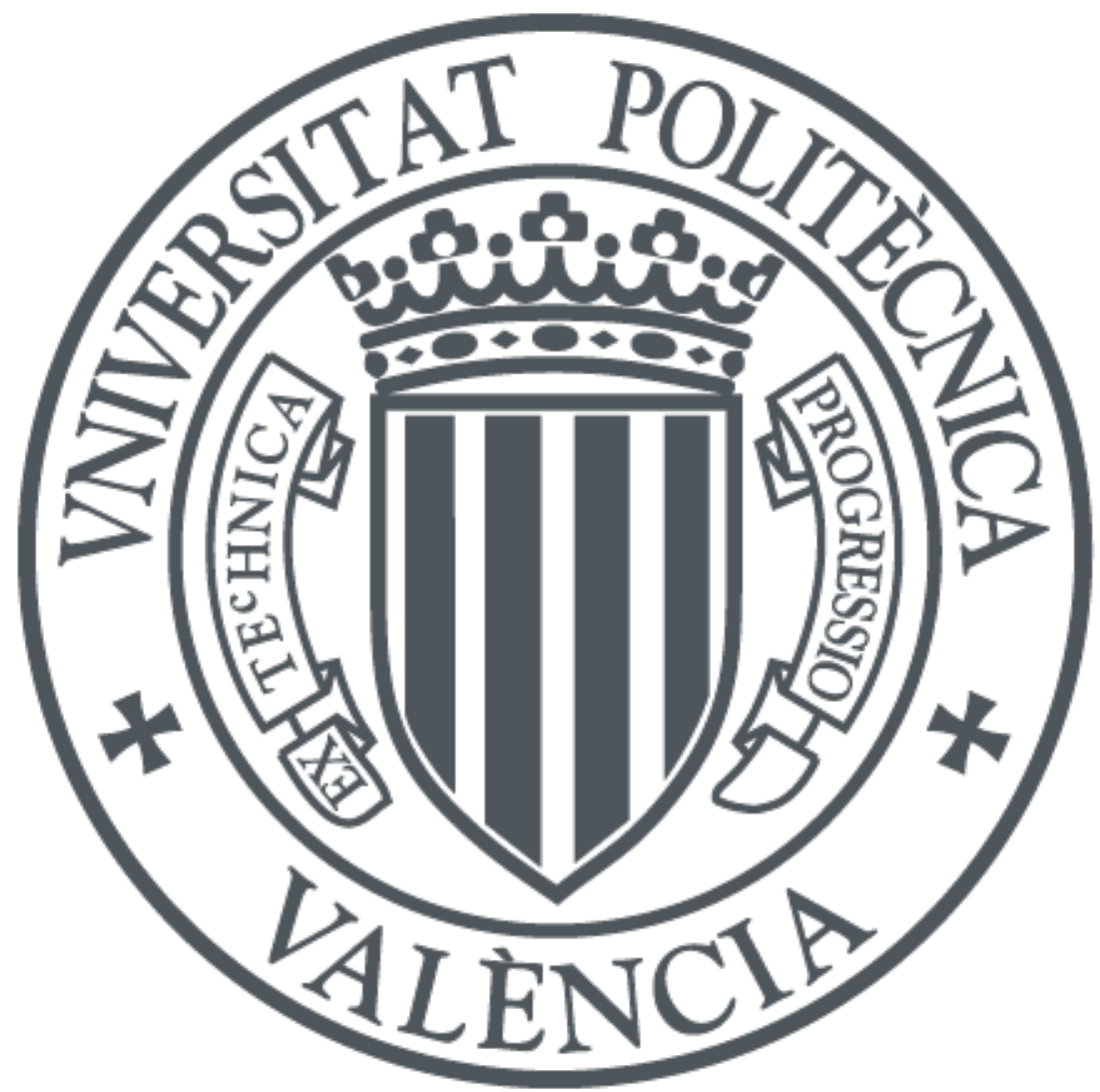

The final publication is available at

http://dx.doi.org/10.1039/c3sc22310h

Copyright Royal Society of Chemistry

Additional Information 


\title{
In Situ Preparation of a Multifunctional Chiral Hybrid Organic- Inorganic Catalyst for Asymmetric Multicomponent Reactions
}

\author{
Pilar García-García, ${ }^{\text {a }}$ Alexandre Zagdoun, ${ }^{\text {b }}$ Christophe Copéret, ${ }^{\mathrm{c}}$ Anne Lesage, ${ }^{\mathrm{b}}$ Urbano Díaz, ${ }^{\mathrm{a}}$ Avelino \\ Corma*a
}

A chiral mesoporous organosilica material incorporating a urea based-cinchona derivative and propylamine groups was prepared by a co-condensation method. The multisite solid catalyst efficiently promoted the asymmetric multicomponent reaction of aldehydes, malonates and nitromethane.

\section{${ }_{10}$ Introduction}

Multicomponent reactions are the most efficient chemical procedures for the synthetic preparation of organic compounds. ${ }^{1-3}$ This approach is particularly attractive as it enables the production of highly elaborated compounds from raw materials in 15 an economical, energy-saving, and intensified manner, avoiding intermediate purification steps. Asymmetric multicomponent reactions ${ }^{4}$ are of growing interest and their potential have been recently expanded by the introduction of chiral small organic molecules as highly efficient catalysts. ${ }^{5}$ In this regard, and as far

20 as we know, all of the developed methodologies make use of homogeneous catalysts and many of them involve nucleophilic addition to an in situ formed imine. ${ }^{6}$ Another strategy exploits the ability of chiral amine catalysts to combine two modes of catalytic activation of carbonyl compounds (iminium and

25 enamine catalysis) easing highly enantioselective Michael-type multicomponent processes. ${ }^{7-9}$ Some other multicomponent reactions mediated by chiral homogeneous organocatalysts have been reported. ${ }^{10-13}$

In the domain of catalyst mediated reactions, heterogeneous 30 catalysis is often preferable to homogeneous catalysis because of the easy separation of the catalyst from the reaction medium and reuse. Furthermore, solid catalysts are specially suited for the design of continuous stirred-tank reactor (CSTR) or fixed bed continuous flow processes. $^{14}$ The extraordinary pace of 35 innovation and progress in asymmetric homogeneous catalysis contrasts profoundly with asymmetric heterogeneous procedures. A commonly used strategy in asymmetric heterogeneous catalysis involves the heterogeneization of a successful homogeneous catalyst by covalent linkage to an inorganic oxide support or

40 organic polymer. It is frequently observed that the new solid catalyst exhibits lower performance compared to the homogeneous counterpart in terms of activity, selectivity and enantioselectivity. Therefore, the development of asymmetric heterogeneous catalyzed procedures is an active area of research

45 that can be of particular interest if one could achieve highly enantioselective reactions. ${ }^{15-16}$

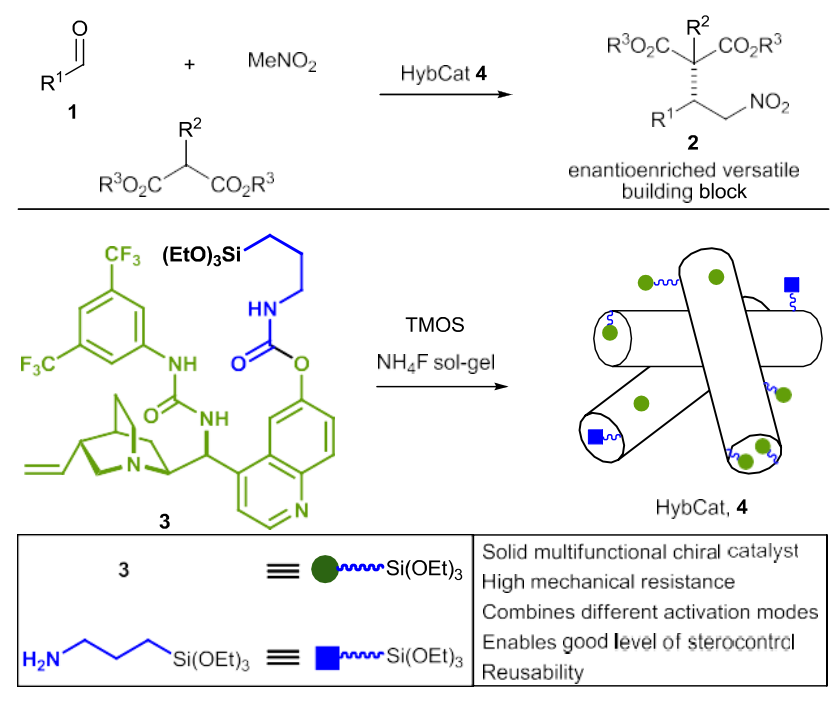

Figure 1. Asymmetric multicomponent reaction promoted by hybrid catalyst 4. TMOS $=$ tetramethylorthosilicate.

50 With regards to asymmetric heterogeneous organocatalysis, several reports have successfully accounted for the heterogeneization of various catalysts ${ }^{17}$ such as proline, ${ }^{18-19}$ diaryl prolinol, ${ }^{20-21}$ MacMillan imidazolidinones, ${ }^{22-23}$ chiral binaphthyl derived phosphoric acids, ${ }^{24-25}$ squaramides, ${ }^{26}$ and cinchona-based 55 organocatalysts. ${ }^{27-30}$

Nevertheless, the use of chiral solid catalysts has been limited to two component reactions and applications to asymmetric multicomponent procedures have been elusive. Here we report our approach towards meeting this challenge. Specifically, the 60 unprecedented application of a chiral heterogeneous catalyst in the enantioselective multicomponent reaction of aldehydes, nitromethane and malonates (Figure 1) is herein documented.

\section{Results and discusion}

We focused our attention on cinchona-based organocatalysts. It ${ }_{65}$ has been recently established that derivatives bearing a (thio)urea 
<smiles>C=CC1CCC1N1CCC1C[C@H](N)c1ccnc2cc(O)ccc12</smiles>
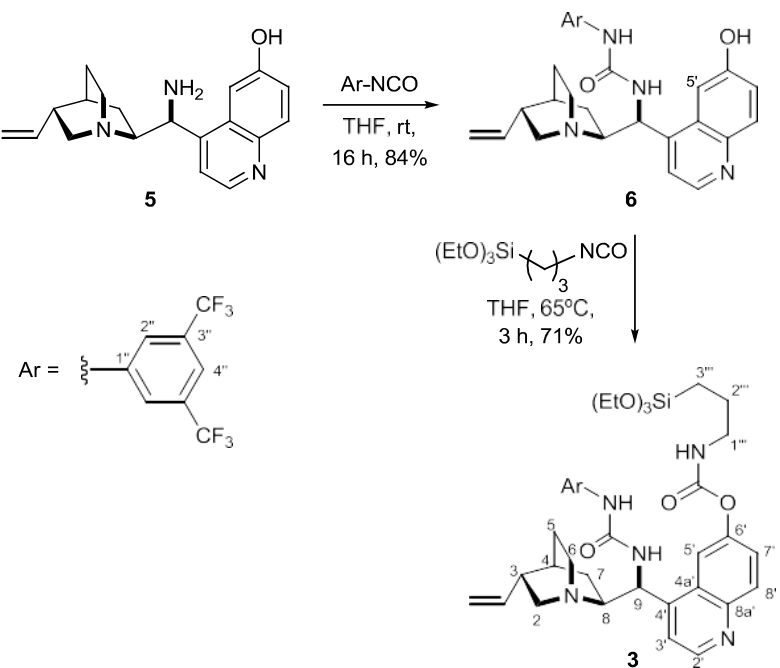

Scheme 1. Synthesis of trialcoxysilyl urea-based cinchona alkaloid derivative 3 .

functional group are general and effective hydrogen bond 5 activators of imines, carbonyl and nitro compounds. ${ }^{31-33}$ The unique ability of this organocatalyst to engage in general-base plus hydrogen bonding catalyzed stereoselective transformations makes it an interesting candidate for heterogeneization. ${ }^{34-35}$

With this in mind, we synthesized first the trialkoxysilylated 10 urea-based cinchona alkaloid derivative 3 (Scheme 1). The known primary amine $\mathbf{5}$, prepared from quinine in two steps, ${ }^{36-37}$ was reacted with 3,5-bis(trifluoromethyl)phenyl isocyanate in THF at room temperature to form the urea derivative 6 in $84 \%$ yield. Subsequent reaction with 3-(triethoxysilyl)propyl 15 isocyanate afforded silylated product $\mathbf{3}$ isolated after column chromatography in $71 \%$ yield and used it in the preparation of a hybrid organic-inorganic mesoporous material (Figure 1).

The incorporation of the organocatalyst in the structure of the mesoporous silaceous material was achieved through co${ }_{20}$ condensation of silylated precursor $\mathbf{3}$ and tetramethylorthosilicate (TMOS). The synthesis of mesoporous structured materials is normally done by means of a surfactant that acts as structure directing agent and synthetic conditions of around $90^{\circ} \mathrm{C}$ and either acidic or basic $\mathrm{pH}$. However, in our case, such conditions

25 and the ulterior removal of the surfactant can introduce irreversible transformations in the organic molecule that may result in a loss of chirality and/or activity. Therefore, we have used here a soft synthetic method ${ }^{38}$ that involves a sol-gel procedure catalyzed by very small amounts of $\mathrm{NH}_{4} \mathrm{~F}$, in absence 30 of structural directing agents, at low temperature and at neutral $\mathrm{pH}$, to obtain the hybrid organic-inorganic mesoporous material (see ESI for details).

The presence of the organic component in the silica framework was confirmed by elemental and thermogravimetrical analysis 35 and by NMR spectroscopy. The content of $\mathrm{C}$ and $\mathrm{N}$ in the solid measured by elemental analysis (Table S1 in the ESI) is an evident probe of the incorporation of the bifunctional catalyst in the material, as the latter was prepared in the absence of structural directing agents. Moreover, the $\mathrm{C} / \mathrm{N}$ molar ratio $\left(\mathrm{C} / \mathrm{N}_{\mathrm{HybCat}}=6.1\right)$ 40 is near to the theoretical value $\left(\mathrm{C} / \mathrm{N}_{\text {theoretical }}=6.4\right)$, indicating that the organic fragments are preserved.

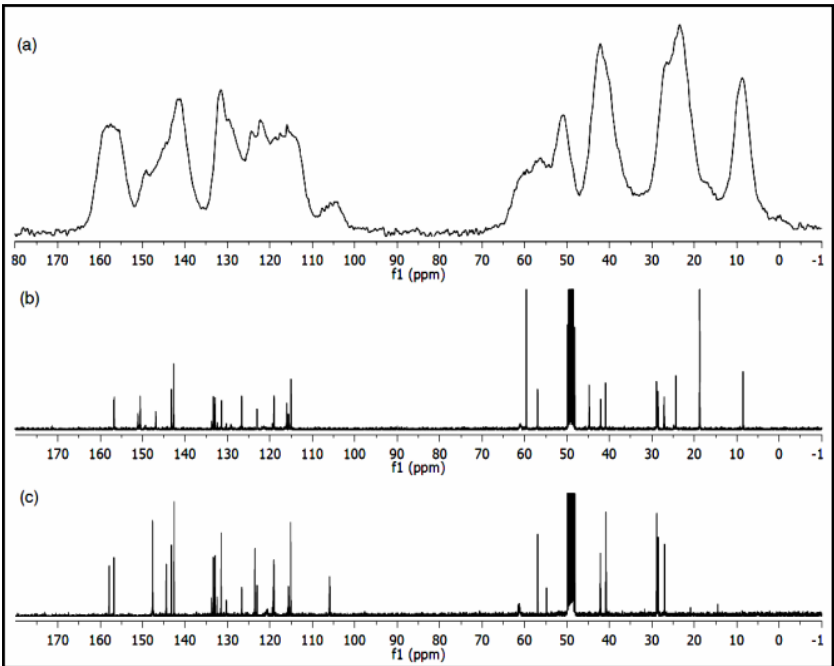

Figure 2. (a) ${ }^{13} \mathrm{C}-\mathrm{CP}$ MAS NMR of HybCat 4. (b) ${ }^{13} \mathrm{C}$ NMR of derivative 3 in $\mathrm{MeOH}-\mathrm{d}_{4}$. (c) ${ }^{13} \mathrm{C}$ NMR of derivative 6 in $\mathrm{MeOH}-\mathrm{d}_{4}$

${ }_{45}$ Organocatalyst content $\left(0.78 \mathrm{mmolg}^{-1}\right)$ in the material was established from the N\% content. Thermogravimetric analysis (Figure S1 in the ESI) was performed in order to gain insight, not only on the organic content present in the solid, but also on the thermal stability of the organic units. Apart from the weight loss

50 observed at around $50-100^{\circ} \mathrm{C}$ associated to the removal of physisorbed water, the main weight loss corresponds to the organic moieties and occurs at temperatures above $150^{\circ} \mathrm{C}$.

The solid-state ${ }^{13} \mathrm{C}$ cross-polarization magic angle spinning (CPMAS) NMR spectrum of the solid is shown in Figure $2 \mathrm{a}$ and ${ }_{55}$ compared with the corresponding ${ }^{13} \mathrm{C}$ spectrum of precursor 3 in

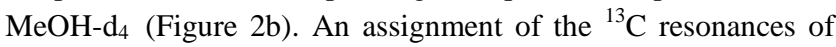
the solid material is proposed from a two-dimensional (2D) shortrange ${ }^{1} \mathrm{H}-{ }^{13} \mathrm{C}$ heteronuclear correlation (HETCOR) spectrum (Figure $3 \mathrm{~A}$ ) and from the solution chemical shifts of compound $\mathbf{3}$ 60 (Figures S23-S30 in the ESI). This assignment is reported in Figure 3. The signal positions observed in ${ }^{13} \mathrm{C}$ CPMAS NMR (Figure 2a) are in good agreement with those of derivative $\mathbf{3}$ (Figure 2b), showing the peaks corresponding to the carbonyl groups of the urea and carbamate moiety, the aromatic and the

65 quinuclidine signals, which confirms the preservation of the structure of the organic molecules during the experimental conditions used for the preparation of the hybrid solid. The signal at $18.7 \mathrm{ppm}$ observed in liquid ${ }^{13} \mathrm{C}$ NMR for derivative 3 (Figure $2 \mathrm{~b}$ ), corresponding to the methyls in the triethoxysilyl groups is ${ }_{70}$ barely observed in solid ${ }^{13} \mathrm{C}$ CPMAS NMR of the hybrid material 4 (Figure 2a), evidencing that hydrolysis of these groups has occurred. ${ }^{13} \mathrm{C}$ CPMAS NMR Spectroscopy proves thereby the integrity of the organic moieties, but it is from ${ }^{29} \mathrm{Si}$ NMR spectra where it is established the real covalent incorporation of the 75 organocatalyst. Silane precursor 3 exhibits only one peak at -45.6 $\mathrm{ppm}$, while in the solid, the signal corresponding to silicon atoms bonded to carbon units are shifted to -57 and -67 ppm (Figure S4 in the ESI) showing the effective attachment of organic linkers by covalent interaction between surface silanol groups and terminal 80 alkoxide units of organosilane.

We were concerned however, by the presence of a peak at 105 ppm in ${ }^{13} \mathrm{C}$ CPMAS NMR spectrum of the solid material that was not observed for the organosilane precursor 3 (Figure 2), and 


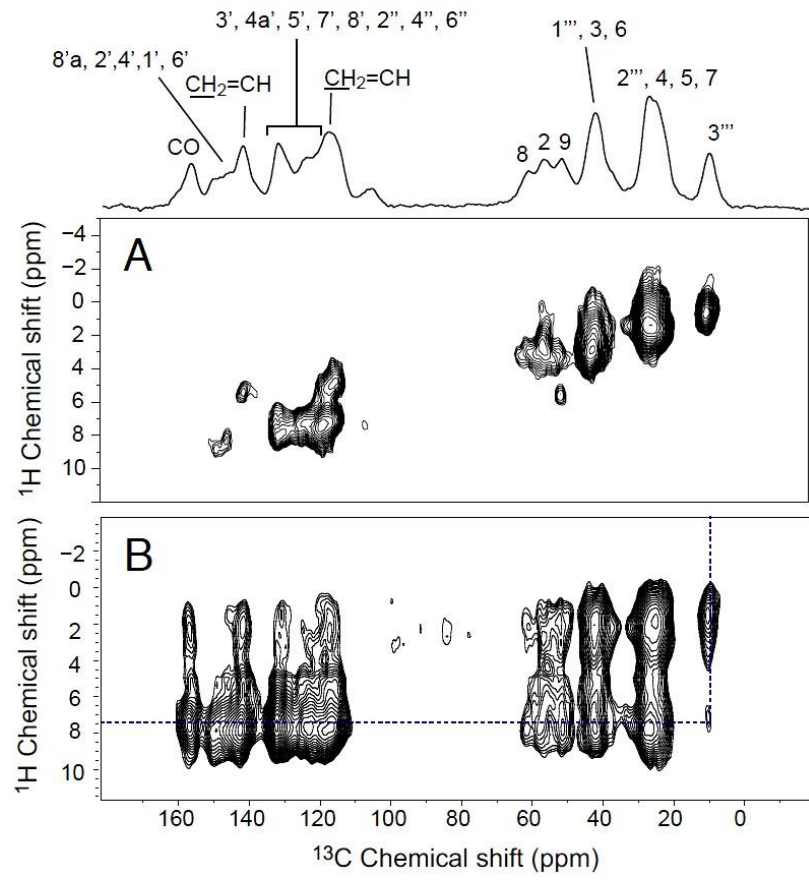

Figure 3. Two-dimensional ${ }^{1} \mathrm{H}-{ }^{13} \mathrm{C}$ HETCOR spectra on HybCat 4 recorded with a $\mathrm{CP}$ contact time of $0.25 \mathrm{~ms}$ (A) and of $2 \mathrm{~ms}$ (B). Other experimental details are given in the ESI. The one-dimensional carbon-13 CPMAS spectrum is shown above the $2 \mathrm{D}$ plots together with the assignment of the resonances.

could suggest that carbamate cleavage has occurred, as the free phenol derivative 6 shows the same exact peak (105.9 ppm, in $\mathrm{MeOH}-\mathrm{d}_{4}$, Figure 2c) assigned to carbon 5 ' in the quinoline 10 moiety.

At this point, we decided to run extensive NMR characterization (see ESI, Figures S5-S7) with the aim of determining if the cinchone derivative is truly covalently attached to the solid material through the carbamate linkage or merely adsorbed in the

15 surface (in the form of derivative 6), with the aminopropyl groups being the ones connected to the surface of the solid material as a result of carbamate hydrolysis.

For doing so, several ${ }^{1} \mathrm{H}-{ }^{13} \mathrm{C}$ HETCOR spectra were recorded with different cross-polarization $(\mathrm{CP})$ contact times to probe 20 long-range spatial proximities between carbon and proton nuclei (Figure 3 and Figure S6 in the ESI). Interestingly, the correlation spectrum of Figure 3B (CP contact time of $2 \mathrm{~ms}$ ) shows a clear correlation between the aromatic protons and the carbon 3', (dotted lines in the plot) suggesting that some of the parent 25 structures are intact in the solid. This was further evidenced by the $1 \mathrm{D}{ }^{19} \mathrm{~F}^{-2}{ }^{29} \mathrm{Si}$ CPMAS spectrum that displays the silicon-29 resonances of both the $\mathrm{Q}$ and $\mathrm{T}$ sites at around -100 and $-60 \mathrm{ppm}$. (Figure S7 in the ESI). This latter resonance is a clear indication of spatial proximities between the $\mathrm{CF}_{3}$ groups and the ${ }^{29} \mathrm{Si} \mathrm{T}$ 30 nuclei.

On the other hand, carbamate hydrolysis was observed for derivative 3 at some extent when running the ${ }^{1} \mathrm{H}$ NMR spectrum in $\mathrm{MeOH}-\mathrm{d}_{4}$ after 24 hours, and also when a catalytic amount of $\mathrm{NH}_{4} \mathrm{~F}$ was added to the NMR tube equating the reaction 35 conditions followed for the preparation of the solid although in the absence of tetramethylorthosilicate. With these results together with the observation of the peak at $105 \mathrm{ppm}$ in ${ }^{13} \mathrm{C}$
CPMAS NMR, we could conclude that the hybrid solid presents the structure depicted in Figure 1, with part of the cinchone-based 40 units covalently attached to the surface and some of them strongly adsorbed to the silaceous surface. Additionally, as a consequence of the partial cleavage, the mesoporous material is functionalized as well with aminopropyl units which ultimately results in a multisite solid catalyst that was envisioned to be 45 applied in a wide range of applications in asymmetric catalysis. As a first illustration, the one reported herein bellow, as an efficient promoter of the enantioselective multicomponent reaction of aldehydes, nitromethane and malonates.

The hybrid organic-inorganic material $\mathbf{4}$ was also analyzed by

50 nitrogen sorption volumetry. Table S2 in the ESI reports surface area, pore volume and mean pore diameter of the hybrid catalyst. The $\mathrm{N}_{2}$ adsorption isotherm (Figure S8 in the ESI), shows the characteristic pattern typical of less-ordered mesoporous materials with the change in the slope occurring at low partial

${ }_{55}$ pressure (P/Po around 0.3). Distribution of pore diameter (Figure S9 in the ESI) reveals that the majority of the pores have a size near to $30 \AA$. From these data, it can be deduced that the hybrid material presents no microporosity and the total surface and pore volume are due exclusively to the presence of mesoporous.

${ }_{60}$ Hybrid material 4 was also analyzed by FTIR spectrometry on self-supporting wafers. The wafer was outgassed at room temperature, $100^{\circ} \mathrm{C}, 200^{\circ} \mathrm{C}$ and $400^{\circ} \mathrm{C}$ before the IR spectra were recorded. The IR spectra at different temperatures are illustrated in the ESI (Figure S10) and compared with that of derivative 3 ${ }_{65}$ (Figure S10, bottom). It should be highlighted that the carbonyl stretching band at around $1720 \mathrm{~cm}^{-1}$ observed for the hybrid solid at room temperature and $100^{\circ} \mathrm{C}$, was not detected at $200^{\circ} \mathrm{C}$, pointing out that organocatalyst degradation is occurring above $100^{\circ} \mathrm{C}$ and therefore confirming the data obtained in the

70 thermogravimetrical analysis. In a different experiment it was analyzed the thermal stability over time at $70^{\circ} \mathrm{C}$ (that corresponds to the reaction temperature used in the catalytic procedure shown below). This study reveals (see the ESI) that the organic moiety endures the temperature conditions used in the multicomponent 75 transformation.

Once secured organocatalyst integrity in the solid material, we envisioned applications as heterogenous catalyst. At first, the hybrid catalyst was tested in the Henry condensation of benzaldehyde $\mathbf{1 a}$ with nitromethane. Amine-functionalized 80 mesoporous materials are known to promote such reaction. ${ }^{39-43}$

In our case, when using $10 \mathrm{~mol} \%$ of organocatalyst loading, the desired nitroalkene 7 was formed after $5 \mathrm{~h}$ reaction time in $51 \%$ yield (eq. 1). Appreciable amounts of the Michael-type addition product 8 were also observed. In addition, the hybrid material 4 85 showcases activity in the asymmetric Michael-type addition of dimethylmalonate to nitroalkenes (eq. 2) and the product was formed in $76 \%$ yield with 91:9 enantiomeric ratio. Thioureabased cinchone derivatives are known to catalyze the latter enantioselective Michael type addition in the homogeneous 90 fase. $^{44-45} \gamma$-Nitro esters $2 \mathbf{a}$ (eq. 2) are versatile building blocks for the synthesis of important nitrogen containing bioactive compounds such as the antidepressant $(R)$-rolipram, ${ }^{46}$ the selective serotonin reuptake inhibitor $(3 S, 4 R)$-paroxetine, ${ }^{46}$ or the antispastic agent $(R)$-baclofren ${ }^{47}$ among many others. ${ }^{48-50}$ 


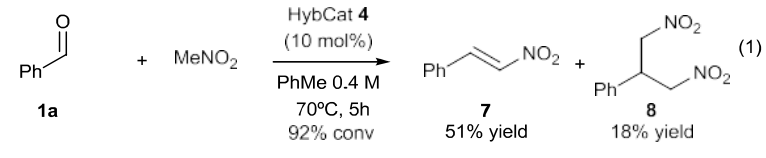

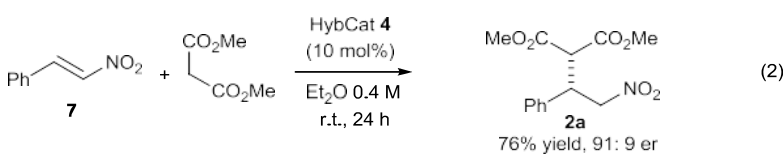

The ability of the solid catalyst to promote the Henry condensation and to impart high stereocontrol in the Michael-type reaction prompted us toward a more challenging target: the

5 creation of multifunctional compounds in a one-pot three component reaction (as shown in Figure 1) where the initially formed nitroalkene could be trapped by dimethylmalonate in a Michael-type addition. Accordingly, the chiral hybrid solid catalyst was used in $10 \mathrm{~mol} \%$ loading at $80^{\circ} \mathrm{C}$ with a mixture of

10 benzaldehyde 1a, nitromethane and dimethylmalonate (data shown in the ESI), and already in the first attempt, the adduct $\mathbf{2 a}$ was obtained in $49 \%$ yield after $8 \mathrm{~h}$ and with 84:16 enantiomeric ratio. Extensive optimization of reaction conditions, i.e. temperature, catalyst loading, solvent, concentration and reagents 15 ratio are reported in Tables S3-7 within the ESI, and the best result is displayed in Table 1 (entry 1). Under the optimized conditions, the product $\mathbf{2 a}$ was isolated after $36 \mathrm{~h}$ in $75 \%$ yield and good enantioselectivity (88:12 er). The obtained result is remarkable since the approach not only provides straightforward 20 access to complex and synthetically useful ${ }^{46-50}$ scaffolds in a rapid and atom-economical way but also with high selectivity (see the ESI for details: Knoevenagel adduct was also formed in $10 \%$ yield) and good enantiocontrol. Preliminary kinetic studies were performed and results are displayed in the ESI.

${ }_{25}$ Precedents on the matter three-component reaction are exposed by McQuade et al, ${ }^{51-52}$ who accomplish the transformation combining a microencapsulated primary amine and a nickelbased homogeneous catalyst. In this way, the product derived from benzaldehyde is reported to be formed in $80 \%$ yield after 24 $30 \mathrm{~h}$ reaction time. ${ }^{51}$ While highly promising, this methodology shows still limitations on the substrate scope, particularly for aromatic aldehydes with electronwithdrawing groups. ${ }^{52}$ Furthermore, the asymmetric version, using a chiral nickel complex, is portrayed only with one substrate (335 methylbutyraldehyde) that yields the product in $72 \%$ ee. ${ }^{52}$ Additionally, it should be noted that the nickel catalyst is a homogeneous system and accordingly, related issues of product purification and/or catalyst recycling should be considered. Sartori et al. ${ }^{43}$ have also accounted for the production of 40 compounds 2 from the corresponding aldehydes, by means of a continuous-flow two-step process using a combination of two column reactors packed with different amino-functionalized silica catalysts. No enantioselective version is reported in any case.

Interestingly, when the multicomponent reaction was attempted 45 with the homogeneous catalyst (data shown in the ESI), the desired product 2a was formed in less than $5 \%$ yield. Furthermore, combination of the homogeneous catalyst with 4 ÅMS or Silica 100 under otherwise similar conditions also furnishes the desired product in very low yield. The distinctive ${ }_{50}$ reactivity offered by the hybrid catalyst could be attributed to the presence of the aminopropyl groups on the solid material.
Table 1. Asymmetric multicomponent reaction of aldehydes, nitromethane and malonates

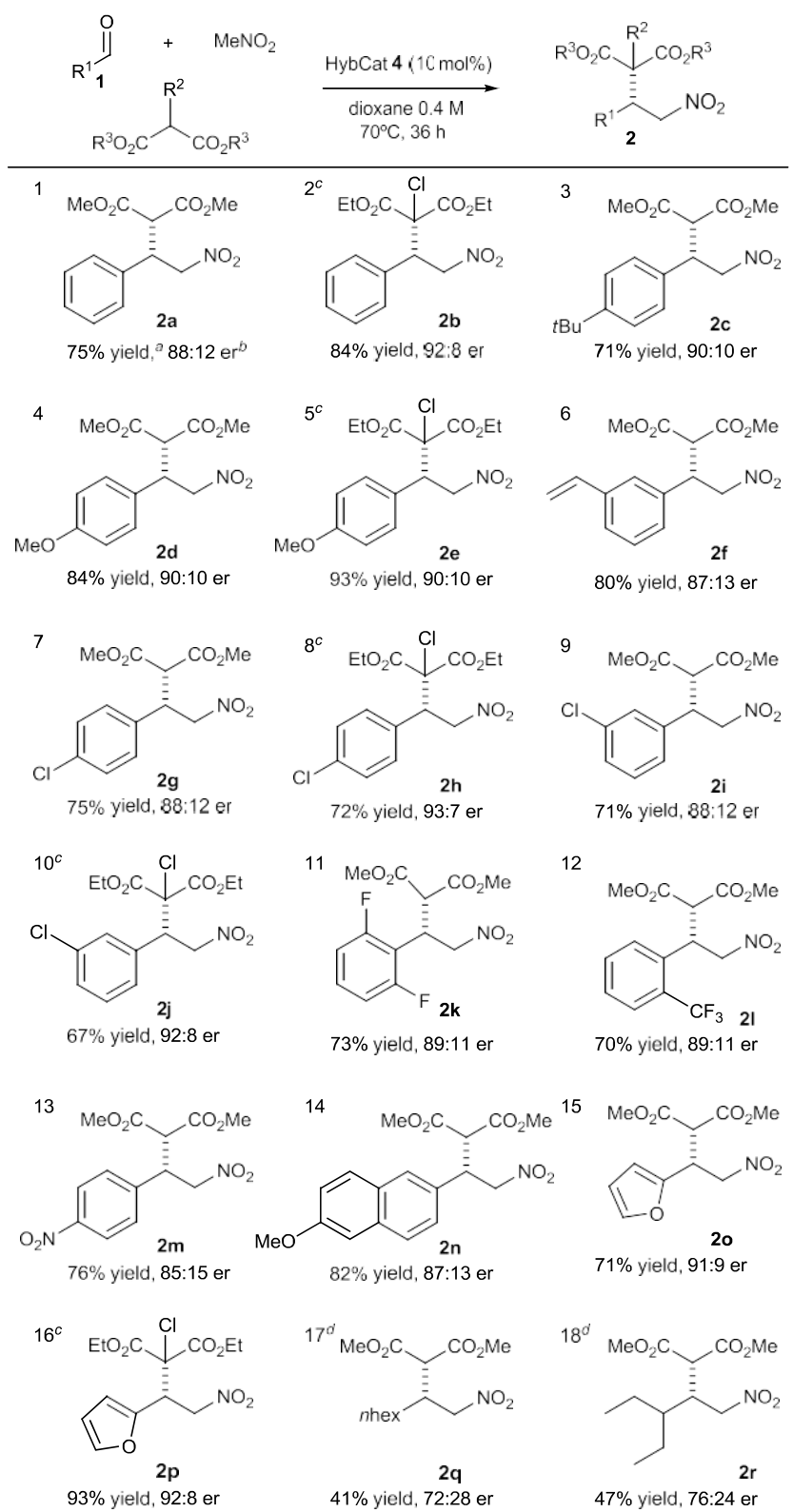

${ }_{55} \mathrm{Y}^{q}$ ield of isolated product. Détermined by HPLC on a chiral stationary phase. ${ }^{c} 1 \mathrm{M}$ concentration and $50^{\circ} \mathrm{C} .{ }^{d}$ Reaction in toluene for $48 \mathrm{~h}$.

The primary amine sites would react with the aldehyde to form an imine intermediate, more prone to be attacked (when compared to ${ }_{60}$ the starting aldehyde) by the deprotonated nitromethane. Addition of nitromethane to the carbon-nitrogen imine bond via an azaHenry process would give a relatively unstable supported $\beta$ nitroamine that after $\beta$-scission produces the nitroalkene and regenerates the aminopropyl site. ${ }^{42}$ The bifunctional cinchona${ }_{65}$ based organocatalyst would then be responsible of the subsequent enantioselective Michael-type reaction. ${ }^{44-45}$

To probe the role of the primary amine group in the multicomponent reaction, two silica materials were prepared by the sol-gel method utilizing $\mathrm{NH}_{4} \mathrm{~F}$ as mineralizing agent. In the 
first place, aminopropyltriethoxysilane was co-condensed with TMOS. The resultant material probed highly efficient in the Henry condensation of aldehydes with nitromethane. Furthermore, when combined with adsorbed organocatalyst $\mathbf{6}$, 5 afforded adduct $\mathbf{2 a}$ in equal yield and enantioselectivity as shown for HybCat 4 under similar reaction conditions (see ESI for details). On the other hand, the siliceous material obtained by cocondensation of diethylaminopropyltriethoxysilane and TMOS showed no activity in the Henry condensation and neither in the

10 three-component reaction when combining it with the adsorbed catalyst 6. These facts additionally account for the presence of primary amine groups in the HybCat 4.

The adsorbed organic molecules $\mathbf{6}$ presented in HybCat $\mathbf{4}$ could be removed (although not completely) by extensive washing of 15 the solid with a solution of AcOEt/MeOH/ $/ \mathrm{NH}_{4} \mathrm{OH}$ 95/5/1 (see Figure S12 in ESI). The resultant material was also tested in the multicomponent reaction demonstrating comparable performance to HybCat $\mathbf{4}$ in terms of both efficiency and enantioselectivity (data shown in the ESI).

20 Adopting the favorable reaction conditions for the asymmetric multicomponent reaction depicted in entry 1 Table 1 , the generality of the method was demonstrated by evaluating a variety of aldehyde and malonate substrates. As highlighted in Table 1, there appears to be significant tolerance toward 25 structural and electronic variations of aromatic aldehydes enabling the access to Michael adducts with good to high yields (70 to 90 s) and high optical purity up to 93:7 enantiomeric ratio. Different substituents at ortho, meta and para positions can be accommodated. Interestingly, electronically different substituents 30 are allowed ranging from electron donating groups to halogens and to stronger electron withdrawing groups. The generality of the method was also verified by using poliaromatic aldehydes (entry 14), as well as heteroaromatic substrates, such as furfural (entries 15 and 16). The enantioselectivity achieved in all cases is 35 similar, oscillating slightly between 85:15 and 93:7 enantiomeric ratio. Aliphatic aldehydes (entries 17 and 18) probed more challenging, though acceptable yields are achieved after $48 \mathrm{~h}$ reaction time forming the desired product in modest enantiomeric ratio (72:28 to $76: 24)$.

${ }_{40}$ Another important aspect of heterogeneous catalysis concerns the stability of the catalyst during recycling runs. This is certainly an advantage with respect to homogeneous catalysis. In our case, the hybrid catalyst was easily separated by centrifugation and reused for further repeating runs.

45 Table 2. Repeated runs using recycled hybrid solid as catalyst.

dioxane $1 \mathrm{M}$
$50^{\circ} \mathrm{C}, 36 \mathrm{~h}$

${ }^{a}$ Determined by ${ }^{1} \mathrm{H}$ NMR using $\mathrm{Ph}_{3} \mathrm{CH}$ as internal stardard. ${ }^{b}$ Determined by HPLC on a chiral stationary phase.
${ }_{50}$ Table 2 shows that the catalytic performance of the hybrid solid remained unchanged throughout the three first runs and catalyst deactivation occurs at run 4 , probably due to organocatalyst degradation and/or leaching after successive submission of the solid material to the thermal conditions used in the reaction (see ${ }_{55}$ ESI for details).

\section{Conclusions}

In summary, we have developed a new multifuctional hybrid organic-inorganic catalyst based on a cinchona alkaloid and aminopropyl groups using a fluoride sol-gel route. The effective 60 incorporation of these organic units was confirmed by different characterization techniques (elemental analysis, TGA, NMR). The novel material was successfully applied to the asymmetric multicomponent reaction between aldehydes, nitromethane and malonates allowing direct access to highly functionalized 65 products in a rapid and atom-economical way and at the same time, in good to high yields as well as good enantioselectivities. The catalyst is stable, easily separable and can be reused several times. We believe that the novel solid material prepared in this work may provide new synthetic possibilities for multicomponent 70 transformations with the consequent preparation of chiral and complex products.

\section{Acknowledgements}

This work was supported by the Spanish Government (Consolider Ingenio 2010-MULTICAT (CSD2009-00050) and MAT201175 29020-C02-01). P.G.-G. is grateful for a JAE-DOC contract from CSIC co-funded by the ESF. The Severo Ochoa program is thankfully acknowledged.

\section{Notes and references}

${ }^{a}$ Instituto de Tecnología Química, UPV-CSIC, Universidad Politécnica 80 de Valencia, Avenida de los Naranjos s/ 46022 Valencia Spain, Fax: (+) 3496 3877809; Tel: (+) 3496 3877800; E-mail: pgargar@itq.upv.es; acorma@itq.upv.es

${ }^{b}$ Centre de RMN à Très Hauts Champs, Université de Lyon (CNRS/ENS Lyon/UCB Lyon 1), 69100 Villeurbanne, France

${ }_{85}$ ETH Zürich Department of Chemistry, Laboratory of Inorganic

Chemistry, CH-8093, Zürich, Switzerland.

$\dagger$ Electronic Supplementary Information (ESI) available: Experimental procedures, complete characterization of the hybrid catalyst and products, NMR spectra, IR spectra, HPLC traces. See DOI: 10.1039/b000000x/

90

1. M. J. Climent, A. Corma and S. Iborra, RSC Adv., 2012, 2, 16-58.

2. , G. N. Sastre and A. Velty, J. Am. Chem. Soc., 2010, 132,1501115021.

3. M. J. Climent, A. Corma and S. Iborra, Chem. Rev., 2010, 111, 10721133.

4. D. J. Ramón and M. Yus, Ang. Chem. Int. Ed., 2005, 44, 1602-1634.

5. G. Guillena, D. J. Ramón and M. Yus, Tetrahedron: Asymmetry, 2007, 18, 693-700.

6. J. Yu, F. Shi and L.-Z. Gong, Acc. Chem. Res., 2011, 44, 1156-1171.

100 7. Y. Huang, A. M. Walji, C. H. Larsen and D. W. C. MacMillan, J. Am. Chem. Soc., 2005, 127, 15051-15053.

8. D. Enders, M. R. M. Hüttl, C. Grondal and G. Raabe, Nature, 2006, 441, 861-863. 
9. P. Galzerano, F. Pesciaioli, A. Mazzanti, G. Bartoli and P. Melchiorre, Ang. Chem. Int. Ed., 2009, 48, 7892-7894.

10. D. B. Ramachary, N. S. Chowdari and C. F. Barbas, Ang. Chem. Int. Ed., 2003, 42, 4233-4237.

5 11. D. B. Ramachary, K. Anebouselvy, N. S. Chowdari and C. F. Barbas, J. Org. Chem., 2004, 69, 5838-5849.

12. D. B. Ramachary and C. F. Barbas, Chem. Eur. J., 2004, 10, 53235331.

13. C. G. Evans and J. E. Gestwicki, Org. Lett., 2009, 11, 2957-2959.

10 14. A. Corma and H. Garcia, Adv. Synth. Catal., 2006, 348, 1391-1412.

15. X. Liu, P. Wang, Y. Yang, P. Wang and Q. Yang, Chem. Asian J., 2010, 5, 1232-1239.

16. P. Wang, X. Liu, J. Yang, Y. Yang, L. Zhang, Q. Yang and C. Li, J. Mater. Chem., 2009, 19, 8009-8014.

15 17. M. Benaglia, in Handbook of Asymmetric Heterogeneous Catalysis, Wiley-VCH Verlag GmbH \& Co. KGaA, 2008, pp. 293-322.

18. D. Font, C. Jimeno and M. A. Pericàs, Org. Lett., 2006, 8, 46534655.

19. A. Zamboulis, N. J. Rahier, M. Gehringer, X. Cattoën, G. Niel, C.

20 Bied, J. J. E. Moreau and M. W. C. Man, Tetrahedron: Asymmetry, 2009, 20, 2880-2885.

20. X. Fan, S. Sayalero and M. A. Pericàs, Adv. Synth. Catal., 2012, 354, 2971-2976.

21. C. A. Wang, Z. K. Zhang, T. Yue, Y. L. Sun, L. Wang, W. D. Wang,

25 Y. Zhang, C. Liu and W. Wang, Chem. Eur. J., 2012, 18, 6718-6723.

22. P. Riente, J. Yadav and M. A. Pericàs, Org. Lett., 2012, 14, 36683671.

23. J. Y. Shi, C. A. Wang, Z. J. Li, Q. Wang, Y. Zhang and W. Wang, Chem. Eur. J., 2011, 17, 6206-6213.

30 24. C. Bleschke, J. Schmidt, D. S. Kundu, S. Blechert and A. Thomas, Adv. Synth. Catal., 2011, 353, 3101-3106.

25. M. Rueping, E. Sugiono, A. Steck and T. Theissmann, Adv. Synth. Catal., 2010, 352, 281-287.

26. P. Kasaplar, P. Riente, C. Hartmann and M. A. Pericàs, Adv. Synth.

35 Catal., 2012, 354, 2905-2910.

27. W. Wang, X. Ma, J. Wan, J. Cao and Q. Tang, Dalton Trans., 2012, 41, 5715-5726.

28. D. Cancogni, A. Mandoli, R. P. Jumde and D. Pini, Eur. J. Org. Chem., 2012, 2012, 1336-1345.

4029 R. P. Jumde, A. Mandoli, F. De Lorenzi, D. Pini and P. Salvadori, Adv. Synth. Catal., 2010, 352, 1434-1440.

30. S. H. Youk, S. H. Oh, H. S. Rho, J. E. Lee, J. W. Lee and C. E. Song, Chem. Commun., 2009, 0, 2220-2222.

31. S. J. Connon, Chem. Eur. J., 2006, 12, 5418-5427.

45 32. W.-Y. Siau and J. Wang, Catal. Sci. Technol., 2011, 1, 1298-1310.

33. H. Miyabe and Y. Takemoto, Bull. Chem. Soc. Jpn., 2008, 81, 785795.

34. P. Yu, J. He and C. Guo, Chem. Commun., 2008,2355-2357.

35. O. Gleeson, G.-L. Davies, A. Peschiulli, R. Tekoriute, Y. K. Gun'ko

$50 \quad$ and S. J. Connon, Org. Biomol. Chem., 2011, 9, 7929-7940.

36. B. Vakulya, S. Varga, A. Csampai and T. Soos, Org. Lett., 2005, 7, 1967-1969.

37. W. Chen, W. Du, Y.-Z. Duan, Y. Wu, S.-Y. Yang and Y.-C. Chen, Ang. Chem. Int. Ed., 2007, 46, 7667-7670.

55 38. U. Diaz, T. Garcia, A. Velty and A. Corma, J. Mater. Chem., 2009, 19, 5970-5979.
39. M. Lakshmi Kantam and P. Sreekanth, Catal. Lett., 1999, 57, $227-$ 231.

40. G. Sartori, F. Bigi, R. Maggi, R. Sartorio, D. J. Macquarrie, M.

60 Lenarda, L. Storaro, S. Coluccia and G. Martra, J. Catal., 2004, 222, 410-418.

41. Q. Wang and D. F. Shantz, J. Catal., 2010, 271, 170-177.

42. K. Motokura, M. Tada and Y. Iwasawa, Ang. Chem. Int. Ed., 2008, 47, 9230-9235.

65 43. L. Soldi, W. Ferstl, S. Loebbecke, R. Maggi, C. Malmassari, G. Sartori and S. Yada, J. Catal., 2008, 258, 289-295.

44. J. Ye, D. J. Dixon and P. S. Hynes, Chem. Commun., 2005, 44814483.

45. S. H. McCooey and S. J. Connon, Ang. Chem. Int. Ed., 2005, 44,

$70 \quad 6367-6370$.

46. P. S. Hynes, P. A. Stupple and D. J. Dixon, Org. Lett., 2008, 10, 1389-1391.

47. T. Okino, Y. Hoashi, T. Furukawa, X. Xu and Y. Takemoto, J. Am. Chem. Soc., 2004, 127, 119-125.

75 48. F. Xu, E. Corley, M. Zacuto, D. A. Conlon, B. Pipik, G. Humphrey, J. Murry and D. Tschaen, J. Org. Chem., 2010, 75, 1343-1353.

49. J.-M. Liu, X. Wang, Z.-M. Ge, Q. Sun, T.-M. Cheng and R.-T. Li, Tetrahedron, 2011, 67, 636-640.

50. P. Elsner, H. Jiang, J. B. Nielsen, F. Pasi and K. A. Jorgensen, Chem. Commun., 2008, 0, 5827-5829.

51. S. L. Poe, M. Kobašlija and D. T. McQuade, J. Am. Chem. Soc., 2006, 128, 15586-15587.

52. S. L. Poe, M. Kobaslija and D. T. McQuade, J. Am. Chem. Soc., 2007, 129, 9216-9221.

85 